\title{
The Two-Dimensional Simulation Study of Flow Pattern near Guiding Wall of Oxidation Ditch
}

\author{
Wei Chen, Mingming Xu \\ College of urban construction, Wuhan University of Science and Technology, Wuhan, China \\ E-mail:weibao7727@126.com \\ Received July 1, 2010; revised August 2, 2010; accepted August 15, 2010
}

\begin{abstract}
Guiding wall is used to change the flow of the oxidation ditch as supporting structure, it widely uses eccentric setting, and its setting parameters are mostly empirical judgments. According to fluent software that simulates the velocity distribution of the guiding wall, to discuss the settings of the guiding wall in different length of downstream extension, eccentricity and guiding wall radius, so to work out its optimized settings.
\end{abstract}

Keywords: Guiding Wall, the Length of Downstream Extension, Eccentricity, Simulation

\section{Introduction}

Oxidation ditch process, with features of longer water residence time, lower organic loading, longer sludge age, as well as energy-saving, is one of the conventional processes of city sewage treatments. The forms of oxidation ditch are varied, but all through the guiding wall to guide the cycling flow of sewage in the ditch to form deviation, so as not to make a lot of sediment in the corners. Therefore, the settings of the guiding wall decide the severity of the sludge deposits and sewage treatment efficiency [1]. At present, it is generally believed that the wall is set to be eccentricity, or guiding wall and the corner are centered on a different heart, which is to change the role of the uneven velocity distribution of the downstream section to achieve better performance.

In the design specification, the length of downstream extension of the wall is approximately equal to the radius of the diversion wall; the eccentricity is generally around $0.5 \mathrm{~m}$, a maximum of not more than $1 \mathrm{~m}$ [2]. However, in practical engineering design, based on their own engineering experience, the designers take different design parameters. The practice shows that the partial too slow sludge flow rate will cause siltation, make treatment less effective and consume higher energy.

To solve the above problems, we make simulation studies by means of numerical simulation software FLUENT, and then feedback on the actual engineering design.

\section{Numerical Simulation of Guiding Wall}

Fluent is general-purpose CFD software and can accurately simulate fluid flow patterns through the finite volume method and the discrete control equation. We make use of the software Fluent to simulate design of the guiding wall, then to determine the optimal design parameters.

\subsection{Simulation Experiment Design}

The main factors of affecting the guiding wall setting are in three aspects: 1) the downstream length of the guiding wall. A reasonable extension length can effectively regulate water flow velocity distribution to reduce the sludge sedimentation. 2) the eccentricity of guiding wall. Eccentricity will directly affect the area of the wall on both sides and change the flow velocity on both sides, thereby affecting the distribution of water flow. 3) the radius of guiding wall. The radius setting is to change the distribution area on both sides of the curve. With different radius, the flow velocity distribution in the curve is also different. Explore the guiding wall settings to determine the design parameters of the length of downstream extension, the radius of the diversion wall and the eccentricity to improve the efficiency of sewage treatment.

\subsection{Modeling}

The analysis model of oxidation ditch near guiding wall uses a four-Kaluoseer oxidation ditch, every single-groove 
with width of $10 \mathrm{~m}$, with a radius of $5 \mathrm{~m}$, the eccentricity thickness of $250 \mathrm{~mm}$. In order to ensure the smooth straight flow of water, we take straight length of $14 \mathrm{~m}$ in analysis model calculations. Guiding wall analysis modeling is as shown in Figure 1.

The "CECS 112:2000 oxidation ditch design specifications" required the average speed in the ditch should be greater than $0.25 \mathrm{~m} / \mathrm{s}$ [3]. In practical engineering design, no less than $0.3 \mathrm{~m} / \mathrm{s}$ are generally used so that the sludge in oxidation ditch was suspended without precipitation [4]. In the model, the intake water velocity is $0.3 \mathrm{~m} / \mathrm{s}$, the outflow is free. All the boundary conditions in the import and export of the cross section are evenly distributed. The model is divided by quadrilateral grid to form a finite element model, and triangular grid in the wall and larger curvature areas, as shown in Figure 2.

\section{The Analysis of Numerical Simulation Results}

By fluent software simulation, after the sewage through the guiding wall, the flow velocity distribution changes a lot (as shown in Figure 3) .Take $0.3 \mathrm{~m} / \mathrm{s}$ as the demarcation point, the velocity distribution can be divided into high-speed zone and low-speed zone. In the low areas, water flow rate is low, precipitation phenomena may occur, thereby affecting operating conditions of the oxidation ditch; therefore it needs to choose the highest of high-speed zone area. And then choose the best settings elements.

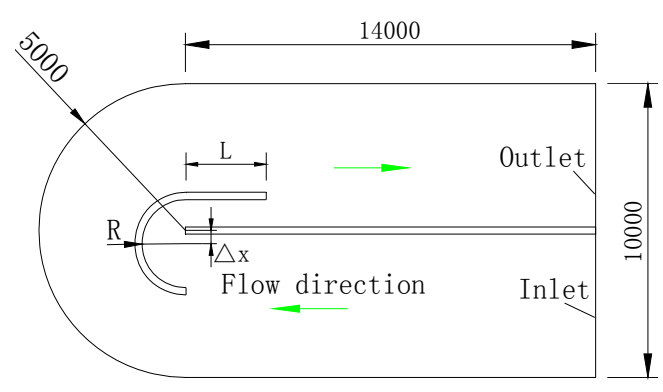

Figure 1. Calculation model of oxidation ditch with eccentric diversion wall.

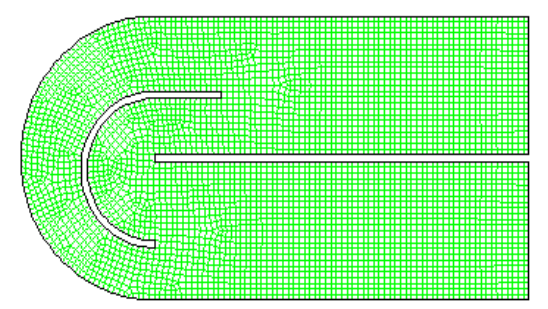

Figure 2. The finite element model with diversion wall.

\subsection{The Setting of Downstream Extension Length}

We take zero-extension length as the base point and 500 $\mathrm{mm}$ as a unit in the model, and simulate by increments to $3500 \mathrm{~mm}$ successively. We use fluent software to analyze the flow properties under different extension length, to verify the best settings length. Statistical velocity distribution in each section is shown as following Table $\mathbf{1 .}$

From Table 1, we can see that at the length of $500 \mathrm{~mm}$ and $2500 \mathrm{~mm}$, under speed in required scope, the area percentages are greatest $68.65 \%$ and $68.64 \%$ respectively. If we choose the extension length of $500 \mathrm{~mm}$, due to the short extension length, it results in a mixture of water at different speeds on both sides and back phenomenon. Therefore, the best downstream extension length in this simulation is $2500 \mathrm{~mm}$, shown in Figure 4; but in practical engineering, the downstream length in oxidation ditch of the same type is also $2500 \mathrm{~mm}$.

\subsection{The Eccentricity Setting}

Eccentricity setting starts from the pool center walls and offset down. We take $100 \mathrm{~mm}$ as a unit, to $700 \mathrm{~mm}$. We use fluent software to simulate velocity distribution conditions, and the statistical velocity distribution is shown as in Table 2.

As can be seen from Table 2, when the eccentricity is $400 \mathrm{~m}$, the water flow in the slow-speed area is fewer, while the percentage of high-speed area is $69.63 \%$, and the sewage precipitation is also lighter, so the eccentricity of $400 \mathrm{~m}$ is more appropriate, which consistent with experience of no more than $0.5 \mathrm{~m}$. Its velocity distribution is shown in Figure 5.

Table 1. The velocity distribution under different downstream extension length.

\begin{tabular}{|c|c|c|c|c|c|c|c|c|}
\hline 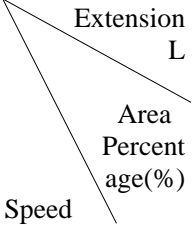 & $0 \mathrm{~mm}$ & $\begin{array}{l}500 \\
\mathrm{~mm}\end{array}$ & $\begin{array}{c}1000 \\
\mathrm{~mm}\end{array}$ & $\begin{array}{c}1500 \\
\mathrm{~mm}\end{array}$ & $\begin{array}{c}2000 \\
\mathrm{~mm}\end{array}$ & $\begin{array}{c}2500 \\
\mathrm{~mm}\end{array}$ & $\begin{array}{c}3000 \\
\mathrm{~mm}\end{array}$ & $\begin{array}{c}3500 \\
\mathrm{~mm}\end{array}$ \\
\hline $0-0.1 \mathrm{~m} / \mathrm{s}$ & 1.93 & 2.79 & 3.60 & 4.01 & 4.18 & 4.40 & 4.54 & 4.88 \\
\hline $0.1-0.2 \mathrm{~m} / \mathrm{s}$ & 9.79 & 9.75 & 9.90 & 10.06 & 9.95 & 9.50 & 9.23 & 8.78 \\
\hline $0.2-0.3 \mathrm{~m} / \mathrm{s}$ & 19.69 & 18.81 & 18.15 & 17.53 & 17.40 & 17.45 & 17.71 & 17.83 \\
\hline $0.3-0.4 \mathrm{~m} / \mathrm{s}$ & 48.84 & 50.03 & 47.92 & 47.45 & 47.22 & 47.42 & 46.94 & 46.74 \\
\hline $0.4-0.5 \mathrm{~m} / \mathrm{s}$ & 19.00 & 17.73 & 19.57 & 20.13 & 20.37 & 20.27 & 20.66 & 20.83 \\
\hline $\begin{array}{c}\text { More than } \\
0.5 \mathrm{~m} / \mathrm{s}\end{array}$ & 0.74 & 0.89 & 0.85 & 0.82 & 0.88 & 0.95 & 0.91 & 0.93 \\
\hline $\begin{array}{c}\text { Total of more } \\
\text { than } 0.3 \mathrm{~m} / \mathrm{s}\end{array}$ & 68.58 & 68.65 & 68.34 & 68.4 & 68.47 & 68.64 & 68.51 & 68.49 \\
\hline
\end{tabular}


Table 2. The speed distribution under different eccentricity.

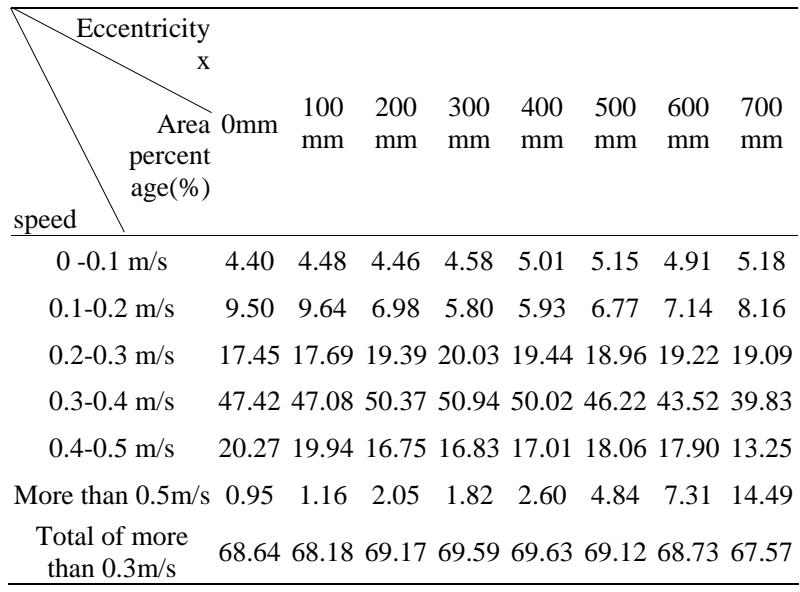

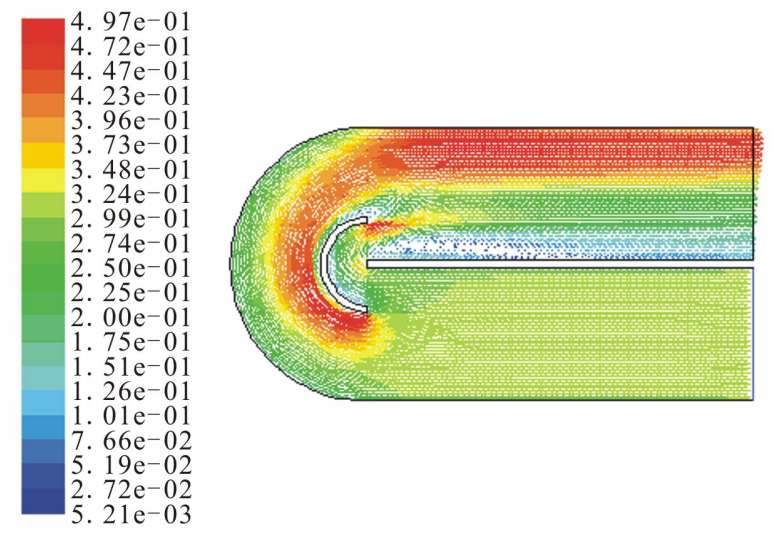

Figure 3. The flow velocity distribution map between the bend.

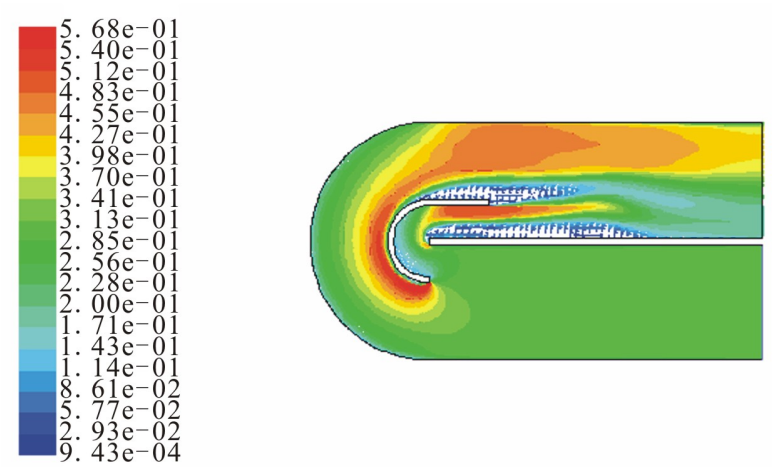

Figure 4. The flow velocity distribution when $L=500 \mathrm{~mm}$.

\subsection{The Radius Settings of Guiding Wall}

The radius change will increase flow velocities in the bend; turbulence levels and increased flushing capacity can reduce the generation of backwater, which can prevent suspended solids from precipitation at back flow in the wall [5].

We take $1000 \mathrm{~mm}$ as the base point and $500 \mathrm{~mm}$ as a radius unit, and then increase to $3500 \mathrm{~mm}$ to simulate the velocity distribution with fluent software .We study the velocity distribution of different radius and the statistical percentage at different speed segments is shown as in Table 3.

As can be seen from the table, when the radius is 1500 $\mathrm{mm}$, the flow rate is more than $0.3 \mathrm{~m} / \mathrm{s}$, that is, the flow high-speed zone occupies a larger area percentage of $69.63 \%$; at this time the diversion wall radius is a superior setting, as shown in Figure 6.

\subsection{The Comparison with the Actual Engineering Guiding Wall Setting}

In practical engineering, the designers mostly set a guiding wall as follows: the extension length $\mathrm{L}$ is equal to the radius $\mathrm{R}$ of $2500 \mathrm{~mm}$, eccentricity is $500 \mathrm{~mm}$. The flow velocity distribution diagram is shown in Figure 7.

Through the comparison of figure 6 and Figure 7, we can see that high-speed zone occupies an area of water $67.43 \%$ in the actual design, lower than the optimal simulation settings. Therefore, the simulated optimiza tion settings can achieve economic savings, better run-ti-

Table 3. The velocity distribution range of different radius.

\begin{tabular}{|c|c|c|c|c|c|c|}
\hline \multirow{2}{*}{$\overbrace{\begin{array}{r}\text { Area } \\
\text { percentage(\%) }\end{array}}^{\text {Radius }}$} & \multirow[b]{2}{*}{$\begin{array}{c}1000 \\
\mathrm{~mm}\end{array}$} & \multirow[b]{2}{*}{$\begin{array}{c}1500 \\
\mathrm{~mm}\end{array}$} & \multirow[b]{2}{*}{$\begin{array}{c}2000 \\
\mathrm{~mm}\end{array}$} & \multirow[b]{2}{*}{$\begin{array}{c}2500 \\
\mathrm{~mm}\end{array}$} & \multirow[b]{2}{*}{$\begin{array}{c}3000 \\
\mathrm{~mm}\end{array}$} & \multirow[b]{2}{*}{$\begin{array}{c}3500 \\
\mathrm{~mm}\end{array}$} \\
\hline & & & & & & \\
\hline $0-0.1 \mathrm{~m} / \mathrm{s}$ & 7.04 & 5.01 & 5.13 & 5.34 & 3.96 & 1.67 \\
\hline $0.1-0.2 \mathrm{~m} / \mathrm{s}$ & 9.97 & 5.93 & 6.28 & 9.96 & 11.17 & 18.58 \\
\hline $0.2-0.3 \mathrm{~m} / \mathrm{s}$ & 13.91 & 19.44 & 20.99 & 19.09 & 23.26 & 19.25 \\
\hline $0.3-0.4 \mathrm{~m} / \mathrm{s}$ & 44.34 & 50.02 & 45.73 & 42.05 & 39.02 & 37.98 \\
\hline $0.4-0.5 \mathrm{~m} / \mathrm{s}$ & 11.52 & 17.01 & 16.86 & 12.57 & 10.48 & 6.70 \\
\hline More than $0.5 \mathrm{~m} / \mathrm{s}$ & 13.22 & 2.60 & 5.02 & 10.98 & 12.11 & 15.82 \\
\hline $\begin{array}{c}\text { Total of more than } 0.3 \\
\mathrm{~m} / \mathrm{s}\end{array}$ & 69.08 & 69.63 & 67.61 & 65.6 & 61.61 & 60.50 \\
\hline
\end{tabular}
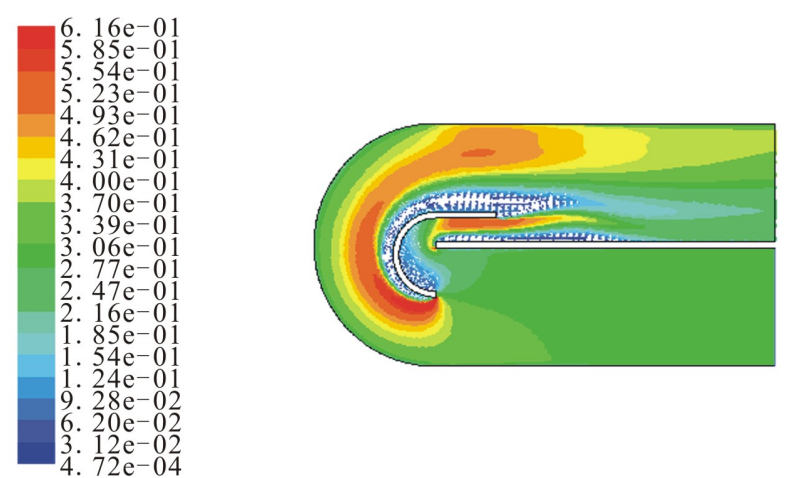

Figure 5. The flow velocity distribution when $\triangle x=400 \mathrm{~mm}$. 

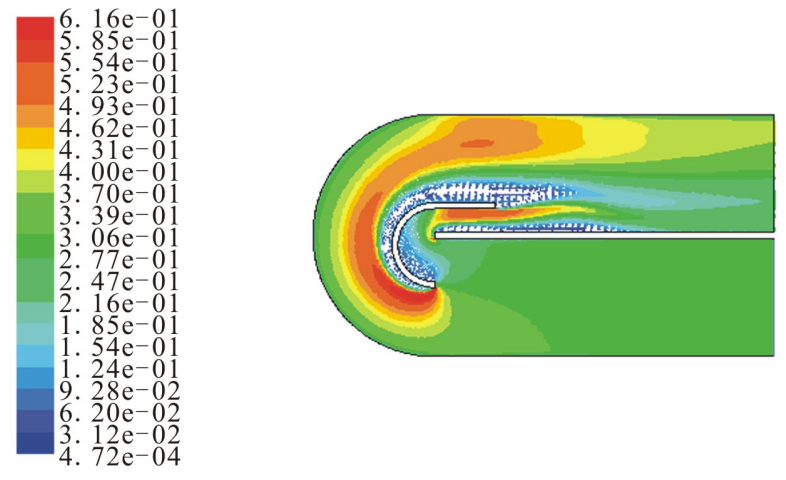

Figure 6. The flow velocity distribution when $R=1500 \mathrm{~mm}$.
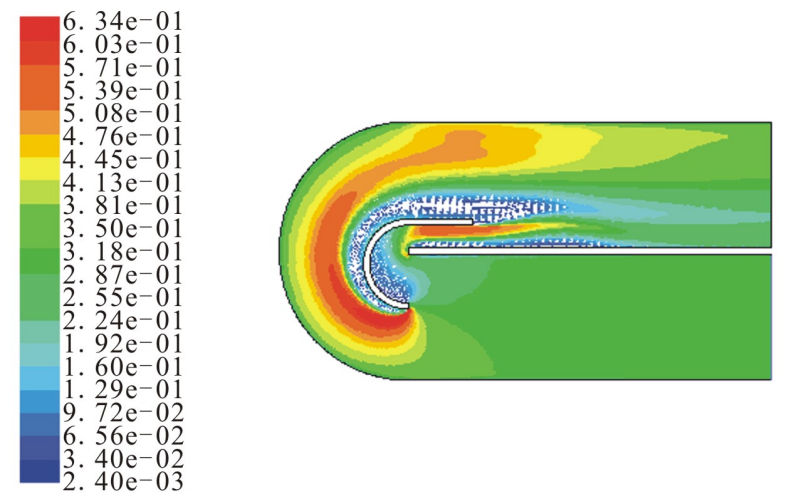

Figure 7. The flow velocity distribution in practical engineering setting.

me flow pattern and ultimately optimize treatment effects.

\section{Conclusions}

1) Through the fluent software simulation of guiding wall and comparation of the size of the speed area percentage, we get optimization setting parameters of the diversion wall three factors: the downstream extension length is $2500 \mathrm{~mm}$, the radius of guiding wall should take $1500 \mathrm{~mm}$, and eccentricity is $400 \mathrm{~mm}$.

2) Prior to the actual engineering design, we can make use of the fluent software simulation for optimal design parameters to guide project design, to maximize the effectiveness of sewage treatment structures.

\section{References}

[1] X. M. Zhao, Q. H. Zhang, T. L. Huang and P. Zhang, "Sludge Sedimentation Curve Analysis and Hydraulic Calculation of Oxidation Ditch," Chinese Water Supply and Drainage, Vol. 24, No. 6, 2008, pp. 38-40.

[2] J. Xu, "On the Research of the Role of Guiding Wall in the Water Structures,” Environment, No. S2, 2006, pp. 135-136.

[3] CECS 112:2000. Oxidation ditch design specifications.

[4] Y. Cao and J. Z. Fu, "Measure to Improve the Oxidation Ditch Velocity Distribution," China Water \& Wastewater, Vol. 17, No. 2, 2001, pp. 16-18.

[5] X. M. Zhao, X. Wang and A. J. Wang, "Oxidation Ditch Bend Flow Characteristics,” Environmental Science and Technology, Vol. 31, No. 4, 2008, pp. 104-106. 